\title{
Impact of Electric Vehicles on Travel and Electricity Demand in Metropolitan Area: A Case Study in Nagoya
}

\author{
Ryo Kanamori ${ }^{1}$, Takayuki Morikawa ${ }^{1}$, Masaya Okumiya ${ }^{2}$, Toshiyuki Yamamoto ${ }^{3}$ and Takayuki Ito $^{4}$ \\ 1. Institute of Innovation for Future Society, Nagoya University, Nagoya 464-8603, Japan \\ 2. Department of Environmental Engineering and Architecture, Nagoya University, Nagoya 464-8603, Japan \\ 3. Eco Topia Science Institute, Nagoya University, Nagoya 464-8603, Japan \\ 4. Department of Computer Science and Engineering, Nagoya Institute of Technology, Nagoya 466-8555, Japan
}

\begin{abstract}
In this study, we examine the impacts that EVs (electric vehicles) have on vehicle usage patterns and environmental improvements, using our integrated travel demand forecasting model, which can simulate an individual activity-travel behavior in each time period, as well as consider an induced demand by decreasing travel cost. In order to examine the effects that charging/discharging have on the demand in electricity, we analyze scenarios based on the simulation results of the EVs' parking location, parking duration and the battery state of charge. From the simulation, result under the ownership rate of EVs in the Nagoya metropolitan area in 2020 is about $6 \%$, which turns out that the total $\mathrm{CO}_{2}$ emissions have decreased by $4 \%$ although the situation of urban transport is not changed. After calculating the electricity demand in each zone using architectural area and basic units of hourly power consumption, we evaluate the effect to decrease the peak load by V2G (vehicle-to-grid). According to the results, if EV drivers charge at home during the night and discharge at work during the day, the electricity demand in Nagoya city increases by approximately $1 \%$, although changes in each individual zone range from $-7 \%$ to $+8 \%$, depending on its characteristics.
\end{abstract}

Key words: Electric vehicle, integrated travel demand forecasting model, electricity demand, V2G.

\section{Introduction}

In order to reduce greenhouse gas emissions such as $\mathrm{CO}_{2}$ (carbon dioxide), it is necessary to lower carbonization in the transportation sector, which causes approximately $20 \%$ of the total $\mathrm{CO}_{2}$ emissions in Japan. Since almost $90 \%$ of these emissions are discharged from automobiles alone, it is also important to enhance the penetration level of next-generation vehicles, such as PHVs (plug-in hybrid vehicles) or EVs (electric vehicles), in addition to normal transport policies that optimize traffic flow, promote the utilization of public transport, and the efficiency of logistics.

In this study, we focus on EVs, and examine their impact on vehicle usage patterns and environmental improvements, using our integrated travel demand

Corresponding author: Ryo Kanamori, Dr., engineer, research fields: travel demand forecasting and travel behavior analysis. E-mail: kanamori.ryo@nagoya-u.jp. forecasting model. The model is able to simulate individual hourly activity-travel behavior in a metropolitan area (in this study, the number of population is over 8 million), and also consider an induced demand by decreasing travel costs due to the difference in electricity and gasoline prices. Moreover, EVs are expected to play an important role as part of the systems in "smart city" because they can serve as electric energy storage devices and provide the power to manage electricity demand or to decrease the peak load by V2G (vehicle-to-grid) technology. On the other hand, the increase in electricity demand due to EV's charging is a concern. Therefore, we calculated the hourly electricity demand in each zone according to its architectural area, using its buildings and the hourly rate of electric power consumption, and examined the effects on the electricity demand due to charging and discharging.

Much research has been carried out in relation to 
the impacts of next-generation vehicles such as "smart city" and "smart grid" and these research topics have been attracted attention in recent years [1, 2]. However, few studies concentrate on the topic of car usage pattern, environmental improvement, and the influences that the introduction of EVs or PHVs has on both travel demand and electricity demand.

Kang and Recker [3] examine the potential energy impacts according to a PHVs usage pattern and charging timing by using sampled activity data from California statewide household travel survey. Dong and Lin [4] use vehicle activity data obtained from a global positioning system. Knapen et al. [5] use daily activity-travel schedule results that are generated by activity-based model FEATHERS (Forecasting Evolutionary Activity-Travel of Households and their Environmental RepercussionS). However, they cannot consider induced effects of PHVs or EVs usage due to changing travel costs because their PHVs or EVs usages are only replicated from conventional vehicle's usage patterns in activity data, not introducing any travel behavior's choice model. On the other hand, Axsen and Kurani [6] survey the consumer's preference to PHV features and estimate the potential energy impacts, and also, they calculate an environment impact [7]. Perujo and Ciuffo [8] also estimate impacts on the electricity supply system and environment in consideration of EV's penetration level and its features in more detail.

\section{Integrated Travel Demand Forecasting Model}

\subsection{Characteristics of Our Model}

The introduction and promotion of EVs are rational as an environmental policy because they do not emit $\mathrm{CO}_{2}$ or $\mathrm{NO}_{x}$ like conventional gasoline cars. On the other hand, since the travel cost of EVs is lower than gasoline cars due to electricity being less expensive than gasoline, it might encourage more car users and cause traffic congestion. Therefore, in order to accurately evaluate urban transport under the condition that EVs become more popular, it is desirable to take into consideration individual travel behaviors (e.g., choice of modes or routes). In this study, the authors have improved their developed travel demand forecasting model, which can simulate hourly activity-travel behaviors for each resident in a metropolitan area $[9,10]$.

In the integrated travel demand forecasting model by Kanamori et al. [9, 10], a traveler's choice behavior in each time period is assumed to be expressed as a nested logit structure, as shown in Fig. 1 (the upper part), which is based on random utility maximization theory and considers activity choice, destination choice, mode choice and route choice behaviors. The model is formulated as the equivalent convex minimization problem-semi-dynamic combined stochastic user
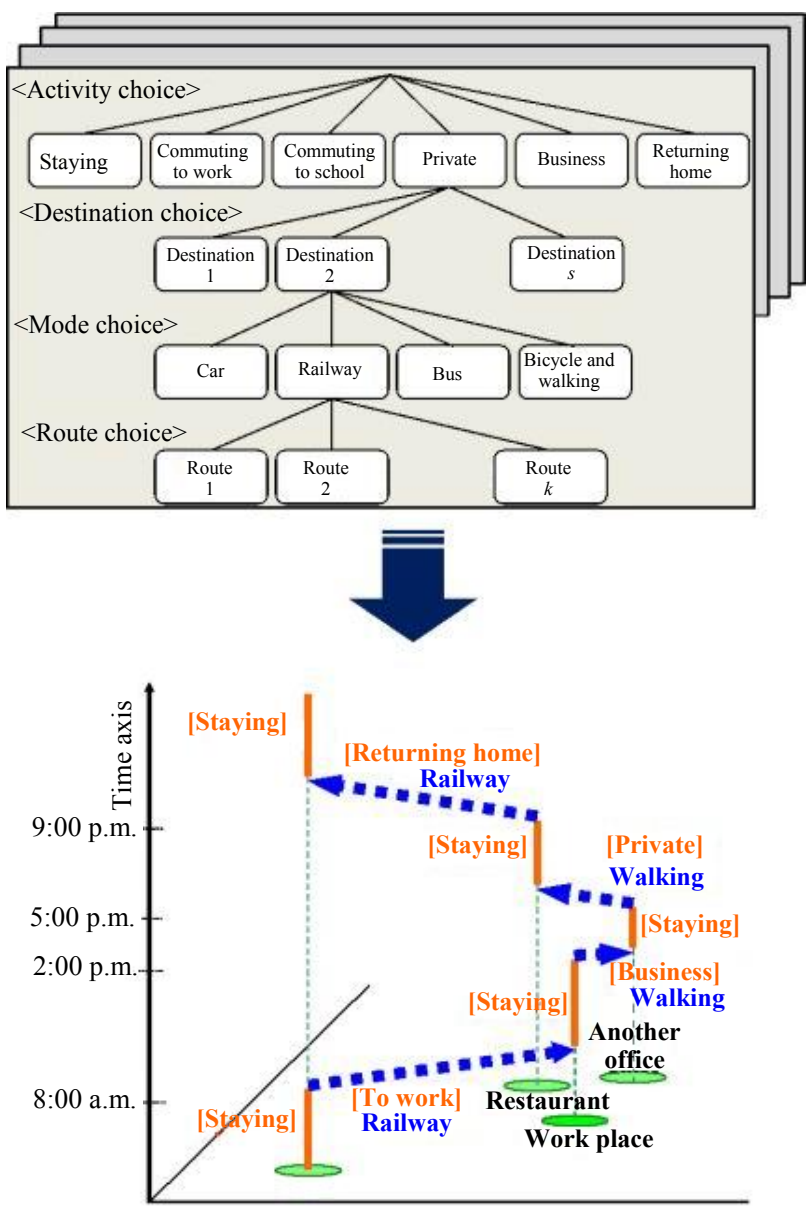

Fig. 1 Decision structure of the traveler choice (upper) and image of time-space path (lower). 
equilibrium model, which can calculate an equilibrium state in each time period between the demand that is aggregated from the travel behaviors of all residents, and the service level of travel time that varies according to the result of traveler behaviors. Thus, this model is able to measure induced traffic by a change in traffic conditions or ownership of vehicle. The time-space path (or the trip chain), as shown in Fig. 1 (the lower part), is reproduced by computing in sequence the equilibrium state in each time period. For this purpose, we deal with activities related to not travelling (or staying), intra-zonal O-D (origin-destination) trips, and walking trips. As a result, the integrated travel demand forecasting model can simulate the spatial and temporal behavior of EV owners in a day (i.e., we can estimate the battery storage levels, arrival and departure time period and parking locations). Although this would normally be explained using formulation, this paper focuses on the impacts to travel demand and the environment.

\subsection{Traveler Behavior}

As mentioned above, individual activity-travel behavior in each time period is expressed as the four levels nested logit model. The activity choice set consists of six alternatives, which are "staying" (i.e., continue to do the same activity at the same location in previous time periods), "commuting to work", "commuting to school", "private", "business" and "returning home", as shown in Fig. 1 (upper part). The traveler then selects a mode from four alternatives (i.e., car, train, bus, and bicycle \& walking) based on the utility function, in which the influence of pre-trip mode for private and business trips, and the leaving home mode for returning home are considered.

The assumption is that the parameter of travel cost in the mode choice model does not change according to whether an individual has ownership of an EV or not, and we prepare the different input data for EVs and gasoline cars, respectively. The basic unit of travel cost is as follows:
- EV: $2.0 \mathrm{JPY} / \mathrm{km}$ (can drive $10 \mathrm{~km}$ per $1.0 \mathrm{kWh}$ [11]);

- gasoline car: $15.0 \mathrm{JPY} / \mathrm{km}$ (can drive $10 \mathrm{~km} / \mathrm{L}$, while the price is $150 \mathrm{JPY} / \mathrm{L}$ ).

The physical constraints and the psychological effects of the driving distance of the EV as per battery capacity were not considered. These issues will therefore be discussed in future studies. However, this model reflects the effects of the cheaper travel cost relating to EVs when it is considered into activity choice level as the log-sum (or inclusive value), in addition to the level of mode choice. Therefore, we can evaluate the induced traffic by increased ownership of EV, utilizing the number of cars in use or the total travel distance in a day.

\subsection{Evaluation Index}

In order to use indices to evaluate the impact of EVs have on urban transport, we compare the vehicle-kilometers, the total travel time, the amount of $\mathrm{CO}_{2}$ or $\mathrm{NO}_{x}$ emissions, and use the data to examine EV usage, parking locations and parking duration. As EVs do not discharge $\mathrm{CO}_{2}$ and $\mathrm{NO}_{x}$, these emissions, which are calculated from the relational expression of velocity $[12,13]$ on each link in the road networks, are added from the gasoline cars only. However, in this study, we include $\mathrm{CO}_{2}$ emissions from charging the EVs' battery, which is displayed as: $\mathrm{CO}_{2}$ emissions from power generation: $41.2 \mathrm{~g}-\mathrm{CO}_{2} / \mathrm{km}$ (basic unit of $\mathrm{CO}_{2}$ emissions from power generation is $0.412 \mathrm{~kg}-\mathrm{CO}_{2} / \mathrm{kWh}$ and $10 \mathrm{~km} / \mathrm{kWh}$ [14]).

\section{Estimation of Hourly Electricity Demand in Each Zone}

Electricity demand differs according to zonal characteristics (e.g., the number of residents, workers, use of buildings, etc.), as well as variations in time and season. In this paper, we estimate the zonal electricity demand according to the architectural area of each building use. Firstly, the monthly electricity demand in each zone is calculated by multiplying the 
architectural area of each building use by the seasonal units set up according to the building use. Next, that demand is then divided into time period levels by the hourly demand curve according to building use. The architectural areas of each building use in the zones are aggregated from the data obtained by GIS (geographical information system).

The seasonal electricity demand units $\left(\mathrm{kWh} / \mathrm{m}^{2}\right)$ and the hourly demand pattern according to building use are set with reference to the manual [15]. Fig. 2 shows the hourly demand patterns in October for each building use (in this study, five buildings categories are used: office, store, hotel, hospital and home). As a result, the electricity demand curve changes significantly according to building use.

As the power demand patterns have taken into account seasonal variations and time variations, which vary depending on the usage of air conditioning, we are able to estimate the electricity demand on any arbitrary day. However, there is only one set value according to standard units of building use (i.e., these values do not change due to the number of people or type of activities). Therefore, we need to take these factors into consideration in future works.

\section{Impact of Electric Vehicle on Urban Transport}

\subsection{Setting}

The area under analysis in this study is the Nagoya

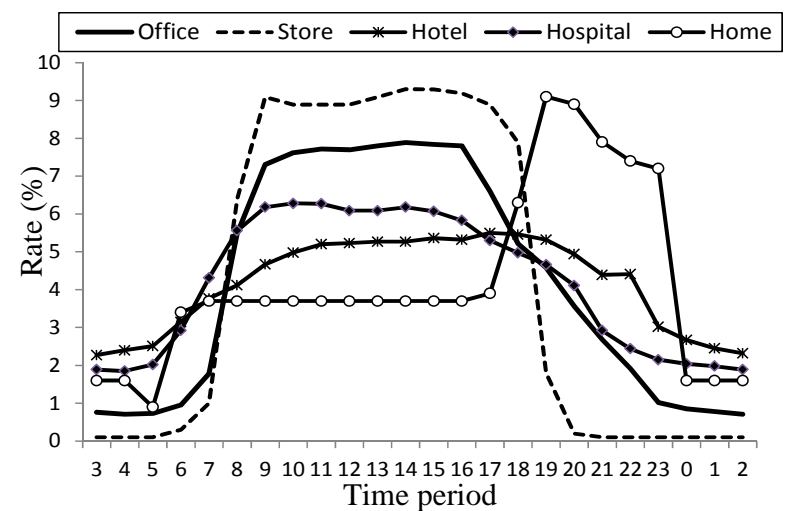

Fig. 2 Hourly demand patterns in October of each building use. metropolitan area (approximately $40 \mathrm{~km}^{2}$ centering on Nagoya city), and has 520 zones. We estimated the night population using the attributes of each zone, and we have also researched separately the individual commuting zone to work/school for our target year 2020. In addition, the parameters of the travel behavior model, which are estimated from person trip survey conducted in 2001, and the network conditions (the number of links is 22,466, etc.) are the same as in our existing research $[9,10]$.

For 2020 , it is projected that $10 \%$ of residents with both a driver's license and a car have ownership of an $\mathrm{EV}$, estimated from the current ownership ratio in Japan (17\% are next-generation car, while there is $3 \%$ $\mathrm{EV})$. As a result, the number of $\mathrm{EV}$ owners in this area, where the total number of residents is approximately eight million, is around 472,000 (i.e., the EV ownership ratio is about 6\%).

\subsection{Impact Analysis of EVs on Urban Transport}

The results in this section are calculated as the average of three 24-hour simulations starting from 3:00 a.m., when all of the residents (8 million people) stay at home. We assume that only EV owners can use their EVs.

Although we examine the simulation results of the total number of trips generated, the share of trip purpose and mode, there are no particular differences when compared with a standard case in which the EV ownership ratio is 0 . It can be said that the impacts of EVs on urban transport are small, when the penetration level is approximately 6\%. Moreover, there is also no difference in the vehicle-kilometers and the total travel time compared with the standard case, although the induced traffic and additional traffic congestion is a concern. The total number of trips per day for EV owners, which is calculated from the results of the activity choice model, is 2.24 trips/day (and 13\% of people do not travel in whole day, i.e., "stay at home" as the concept of stay). Statistically, there is no difference compared with the 
standard case.

From the EVs' total travel distance in a day, the share of short distance trips in which the intra-zonal OD trips and the trips less than $5 \mathrm{~km}$ are categorized is the highest as $45 \%$. As the average travel distance per day is $13.9 \mathrm{~km}$, the limitation of travel distance is sufficient (i.e., about 100 150 km). Conversely, it can be confirmed that the introduction of EVs has reduced the emission effects of $\mathrm{CO}_{2}$ and $\mathrm{NO}_{x}$. $\mathrm{CO}_{2}$ emissions have decreased by approximately $4 \%$, while the power generated by charging EV batteries is $2 \%$ or less.

According to Fig. 3, which shows the hourly activities of all EV owners, it indicates that they are only driving during a small amount of time (the gray part), and that the owners are at home or at work in most of time. Fig. 4 shows the hourly parking location, which is classified into three categories: home, workplace and other places (e.g., near store or hospital). According to Fig. 4, a large number of EVs park at home during the night, although about 30\% also park at home during the daytime. The percentage of EVs parked near workplace during the daytime is between $40 \%$ and $60 \%$, with an average duration of $8.3 \mathrm{~h}$. Thus, this is a good opportunity to manage electricity demand or decrease peak load by utilizing the EV's storage function adequately.

Fig. 5 shows the potential index for parking at the workplace in each zone. When multiplied by the

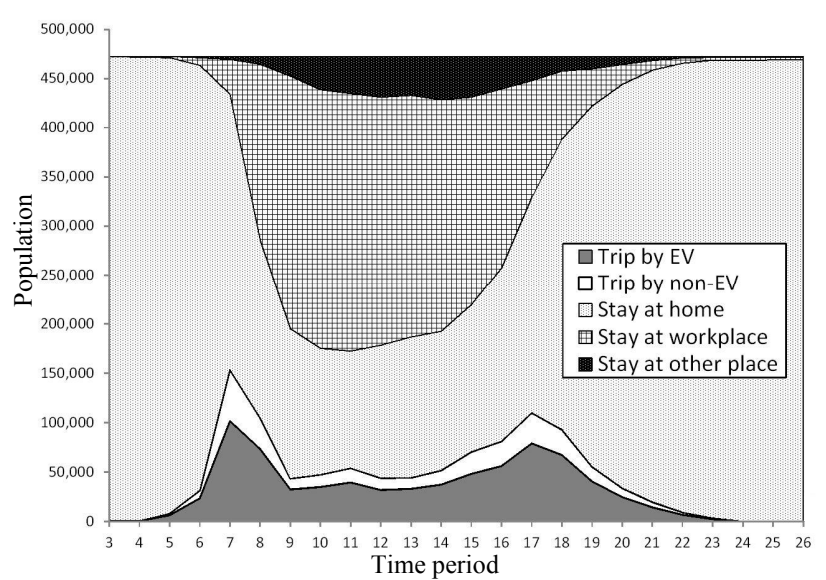

Fig. 3 Hourly activities of all EV owners.

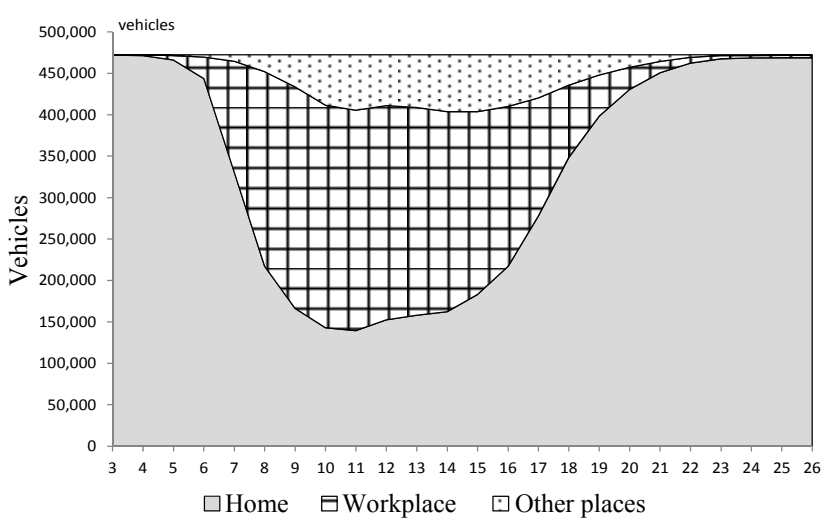

Fig. 4 Hourly parking location of all EVs.

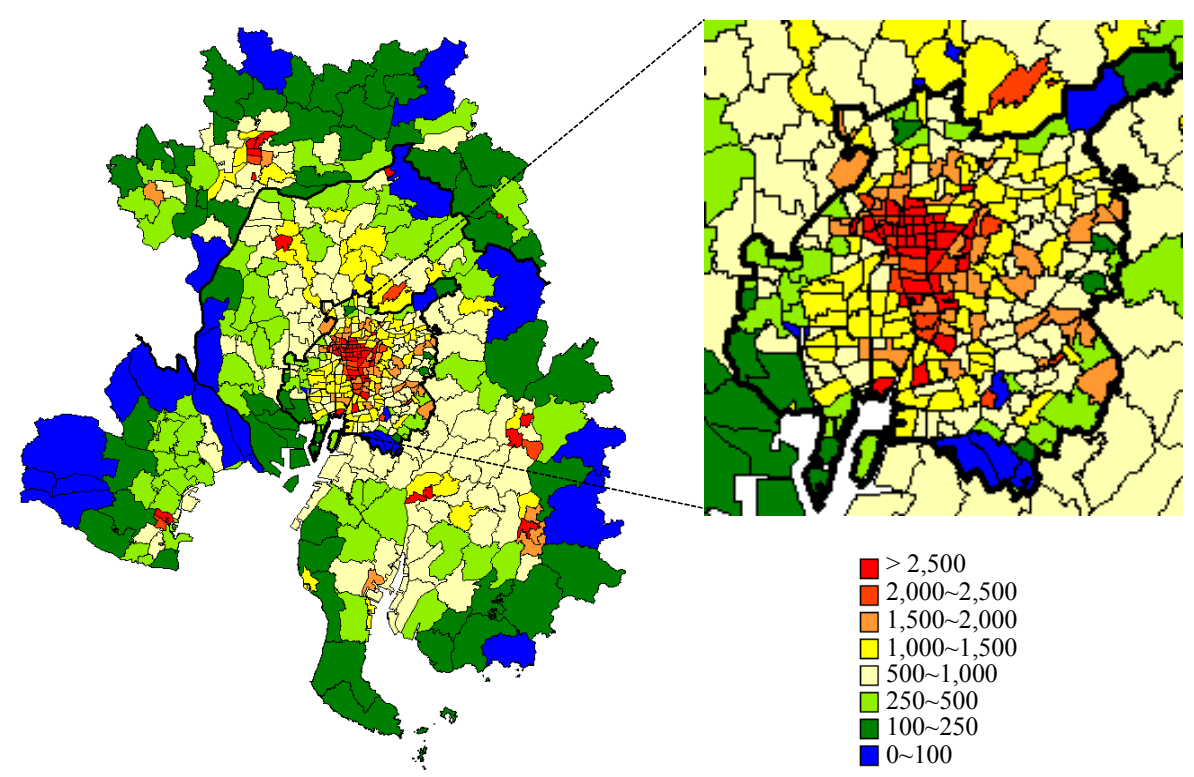

Fig. 5 Potential index for parking at workplace in each zone (vehicle-hours $/ \mathbf{k m}^{2}$ ). 
parking time and the number of parked EVs, we can see that the indexs at the CBD (center business district) in Nagoya, where it is convenient to use rail, are very large, with over 2,500 vehicle-hours $/ \mathrm{km}^{2}$. Since the parking duration at workplace is comparatively long, preparing the facilities for charging/discharging will bring a solution of psychological anxiety for the EVs' driving range, and an effective use of the EVs as V2G. Furthermore, by introducing a road pricing policy for non-EVs, or a sharing system in which visitors to the CBD can have the EVs parked at the workplace during the day, it is also expected that the penetration of EVs will be promoted rapidly.

\section{Impact of Electric Vehicle on Electricity Demand}

\subsection{Electricity Demand in Each Zone}

In this study, the electricity demand of Nagoya city, which has 259 zones, is estimated by using the basic survey of city planning conducted in 2006. The calculation method has been explained in previous sections. In order to maintain consistency with the results of travel demand forecasting, we analyse the electricity demand pattern in October. However, the electricity demand in October is the second smallest (the smallest demand is during May), and the largest demand in August, 1.36 times that of October.

Fig. 6 shows the hourly electricity demand according to building use in Nagoya. The total electricity demand in a day is approximately $31 \mathrm{GW}$, and the time variation in the demand curve is as follows: the demand goes up abruptly at 8:00 a.m., and maintains at about $2 \mathrm{GW}$ until 6:00 p.m., and gradually decreases after that. From the point of view of building use, the peak demand at home occurs during the evening because most residents return and stay in during this time period. On the contrary, the demand at offices and stores reaches its highest point during business hours. The demand at other buildings (such as hotels and hospitals used in this analysis) is constant without peak hours because their equipment needs to be maintained throughout the day and night. According to Fig. 7, which shows the one-day demand in each zone, it turns out that there are higher demands in the CBD, and those in surrounding areas, whose rate of housing is relatively high, are small, just like the result of the parking index shown in Fig. 5.

\subsection{Scenarios of EV Owners' Behavior When Charge/Discharge}

In this study, we evaluate the impact on the electricity demand by the charge/discharge of EVs under the assumption that the EV's energy storage functions will be fully utilized in 2020 (i.e., EV owners can charge or discharge at any time and at any

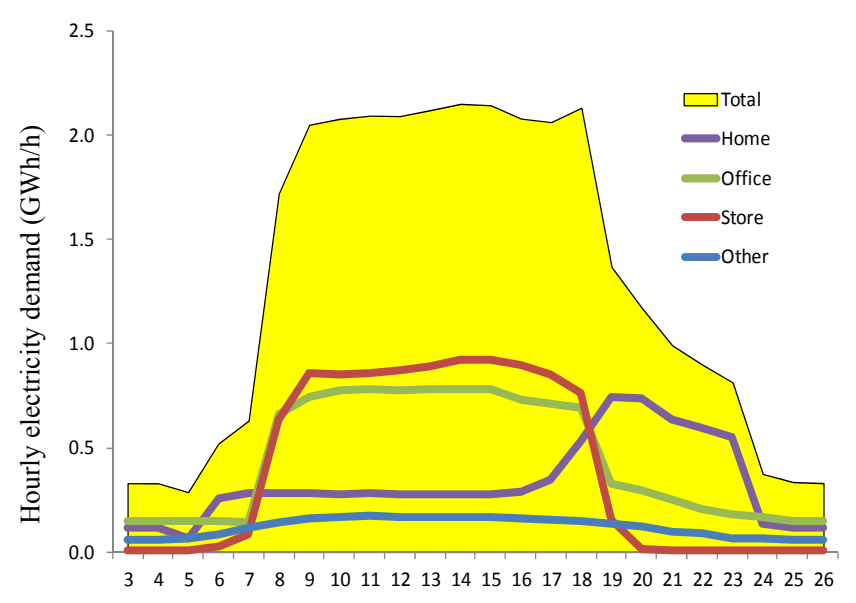

Fig. 6 Hourly electricity demand according to building use of Nagoya.

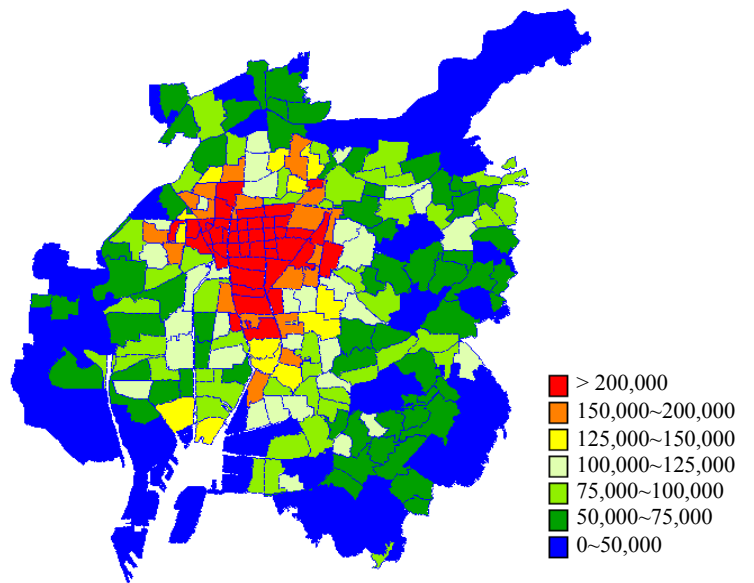

Fig. 7 One-day electricity demand in each zone $\left(\mathrm{kWh} / \mathrm{km}^{2}\right)$. 
location). The scenario to set up is as follows:

- Case 1: without the EVs' charging and discharging;

- Case 2: charge at home immediately after arriving at home each time (no time constraint);

- Case 3: charge at home during night-time only (between 23:00 p.m. and 7:00 a.m.);

- Case 4: charge at workplace immediately after arriving at work each time (no time constraint);

- Case 5: charge at home during night-time and discharge at work-place during daytime (can only charge between 23:00 p.m. and 7:00 a.m., and can only discharge from 9:00 a.m. to 18:00 p.m. and until the battery capacity is $5.0 \mathrm{kWh}$ ).

In addition, EV owners can charge or discharge when staying at the same place for more than $1 \mathrm{~h}$, and do not change his/her activity-travel behaviors due to the EV's level of storage. The assumption is that all EV battery capacity is $20 \mathrm{kWh}$ and the speed of charge and discharge is $1.5 \mathrm{kWh}$ per hour.

\subsection{Impact Analysis of EVs on Electricity Demand}

In this section, the analysis is conducted under the conditions that the remaining battery of all EVs is 14 $\mathrm{kWh}$ at 3:00 a.m. (i.e., the battery is fully charged if it is parked until 7:00 a.m.) and the power consumption of the EV is proportional to O-D distance simply.

As shown in Table 1, the one-day electricity demand in Nagoya increases by $2.51 \%$ in Cases 2 and 3, $1.6 \%$ in Case 4 , and $0.6 \%$ in Case 5 . If owners charge at home under Cases 2, 3, and 5, the time with the largest change is at 5:00 a.m., at which the demand increased by 58\%. Moreover, if charging or discharging at the office (i.e., Cases 4 and 5), the time with the biggest change is 9:00 a.m., where the demand changed about 5\%. Fig. 8 displays the results of the hourly electricity demand in Nagoya for each case. According to the graph, the demand increases by approximately $0.2 \mathrm{GW}$ if the $\mathrm{EV}$ is being charged at home in Cases 2, 3 and 5, although the rate of increase is $58 \%$. Furthermore, when EV owners charge at the workplace during daytime, the increased demand from
9:00 a.m. to midday is around $0.1 \mathrm{GW}$ (about 5\%). In Case 5, where EV owners can discharge at their offices using $\mathrm{V} 2 \mathrm{G}$, the demand from 9:00 a.m. to 16:00 p.m. decreases by about $0.1 \mathrm{GW}$.

Using impact analysis of the electricity demand in each zone, we examine the changes of demand in Case 5. From Fig. 9, it can be seen that the rate of increase in the surrounding areas is over $2.5 \%$, which is average of Nagoya city, and that the rate of decrease in the $\mathrm{CBD}$ is $2.5 \%$ or less. Here, it is Fig. 9 (lower) that aggregated along time axis the number of the EVs parking and the amount of the EVs' charging or discharging in the zones especially whose change in electricity demand is large. Fig. 9 (lower left) shows the results of Zone 601 in which the electricity demand in a day decreases by $6.7 \%$, where the percentage of architectural area is as follows: $18 \%$ home, $40 \%$ office, $1 \%$ store, $41 \%$ other. Due to the fact that most EVs are located at work during the day, the amount of charging at home during night-time is quite small, and the amount of electric discharge during daytime will be approximately $800 \mathrm{~kW}$, thus reducing the total electricity demand. On the contrary,

Table 1 Impact to electricity demand in Nagoya for each case.

\begin{tabular}{llrl}
\hline & All day Max & \multicolumn{1}{l}{ Min } \\
\hline Case 2 & $2.51 \%$ & $57.73 \%(5: 00$ a.m. $)$ & $0.01 \%(8: 00$ a.m. $)$ \\
Case 3 & $2.51 \%$ & $57.73 \%(5: 00$ a.m.) & $1.43 \%(2: 00$ a.m.) \\
Case 4 & $1.56 \%$ & $5.27 \%(9: 00$ a.m.) & $0.01 \%(11: 00$ a.m.) \\
Case 5 & $0.57 \%$ & $57.73 \%(5: 00$ a.m.) & $-5.35 \%(9: 00$ a.m.) \\
\hline
\end{tabular}

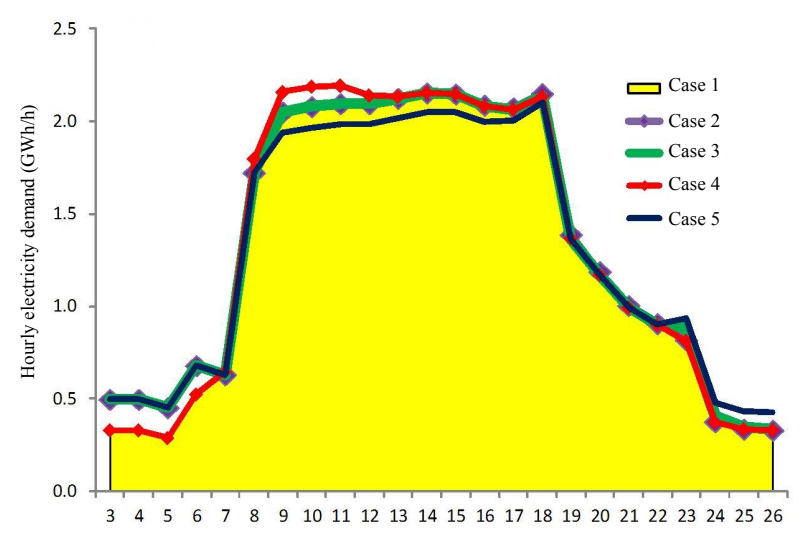

Fig. 8 Results of hourly electricity demand in Nagoya for each case. 


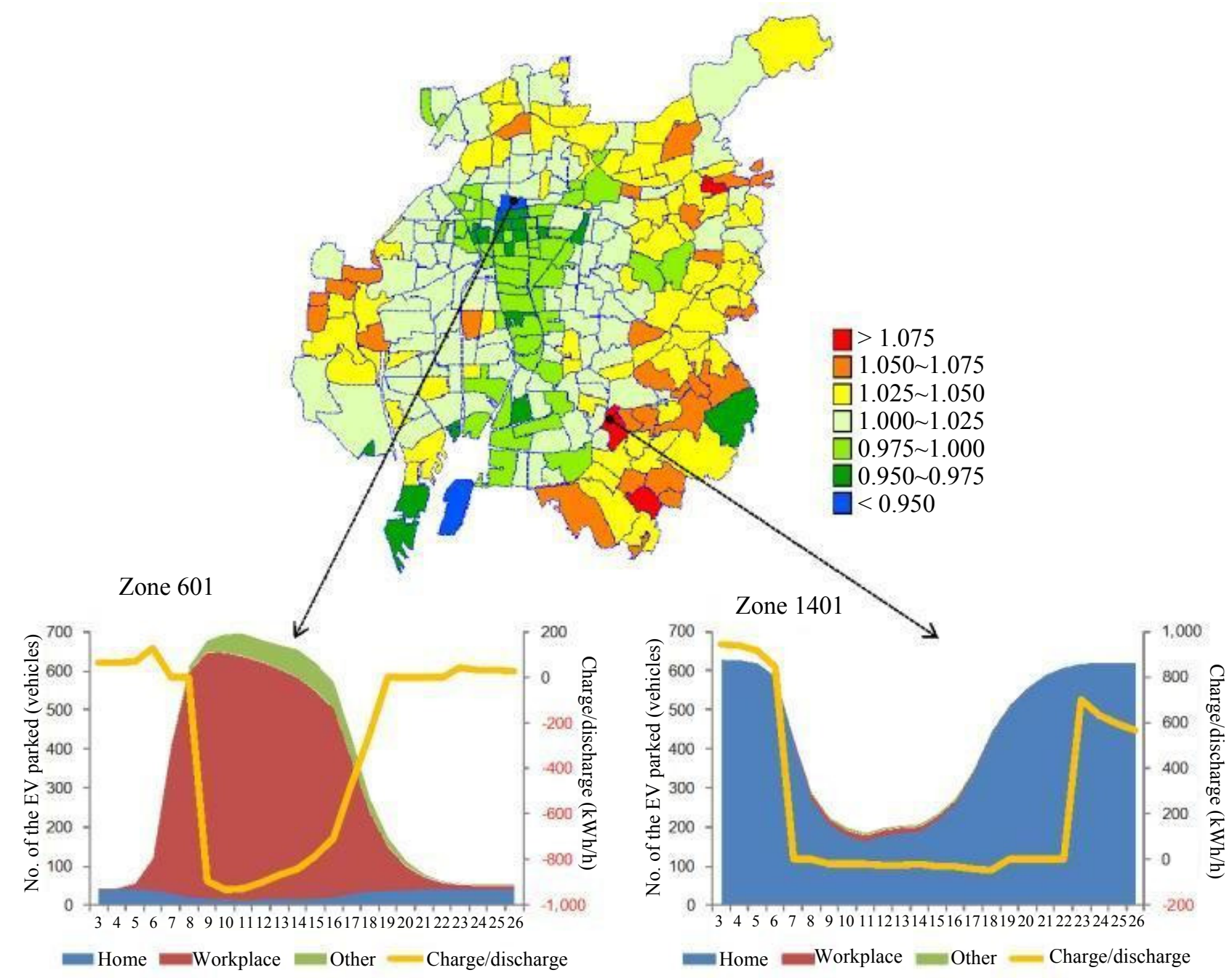

Fig. 9 Changes of electricity demand in each zone (Case 5).

Fig. 9 (lower right) shows the results of Zone 1401, in which the electricity demand during the day increased by $8.0 \%$. This is a residential area because the majority of the architectural areas are residential (87\%).

To simply summarize the impacts on electricity demand in Nagoya city, the changes during daytime are about $5 \%$ when the EV owners charge or discharge. The amount of charges or discharges of EVs in each zone is different according to its characteristics, with a maximum of $800 \mathrm{~kW}$.

\section{Conclusions}

In order to examine the effects of EVs, which can contribute to environmental improvement, we modelled a traffic simulation in the Nagoya metropolitan area, under the assumption that the penetration level of EVs is $6 \%$ in 2020, and analysed the impacts that charging/discharging EVs would have on the city's electricity demand:

- Firstly, the integrated travel demand forecasting model has been improved, which can reproduce an individual activity-travel behavior to take into account differences in travel cost. By applying the results of this model to the Nagoya metropolitan area, it turns out that there are few changes to the situation of urban transport if EVs' penetration level is $6 \%$, and that the total $\mathrm{CO}_{2}$ emissions decreases by $4 \%$;

- Next, the electricity demand in each zone has been calculated according to the architectural area and 


\section{A Case Study in Nagoya}

basic units of hourly power consumption. Next, with the simulation results of the EVs' parking place, parking duration, and battery state, impacts of owners' action of charging/discharging their EVs on the electricity demand have been evaluated. According to the results, electricity demand in Nagoya city during the day increases by $0.5 \% \sim 2.5 \%$ if the EVs are introduced. In the circumstances where the owner can discharge their EVs at work using V2G during daytime, the demand decreases by approximately $5 \%$;

- In terms of future research and studies, the development of a new travel demand forecasting model that can take into account the physical constraints and the psychological effects of the EV's driving distance should be considered, and an improvement in the method used to calculate electricity demand should be implemented. Furthermore, in an effort to manage electricity demand effectively, it is necessary to discuss the incorporate solar energy power generation system, the parking reservation system, and the EV sharing system.

\section{References}

[1] Green, R. C., Wang, L., and Alam, M. 2011. "The Impact of Plug-In Hybrid Electric Vehicles on Distribution Networks: A Review and Outlook." Renewable and Sustainable Energy Reviews 15 (1): 544-53.

[2] Ramchurn, S., Vytelingum, P., Rogers, A., and Jennings, N. 2012. "Putting the 'Smarts' into the Smart Grid: A Grand Challenge for Artificial Intelligence." Communications of the ACM (Association for Computer Machinery) 55 (4): 86-97.

[3] Kang, J. E., and Recker, W. W. 2009. "An Activity-Based Assessment of the Potential Impacts of Plug-In Hybrid Electric Vehicles on Energy and Emissions Using 1-Day Travel Data." Transportation Research Part D 14: 541-56.

[4] Dong, J., and Lin, Z. 2012. "Within-Day Recharge of Plug-In Hybrid Electric Vehicles: Energy Impact of Public Charging Infrastructure." Transportation Research
Part D 17: 405-12.

[5] Knapen, L., Kochan, B., Bellemans, T., Janssens, D., and Wets, G. 2012. "Using Activity-Based Modeling to Predict Spatial and Temporal Electrical Vehicle Power Demand in Flanders." Transportation Research Record 2287: 146-54.

[6] Axsen, J., and Kurani, K. S. 2010. “Anticipating Plug-In Hybrid Vehicle Energy Impacts in California: Constructing Consumer-Informed Recharge Profiles." Transportation Research Part D 15: 212-9.

[7] Axsen, J., Kurani, K. S., McCarthy, R., and Yang, C. 2011. "Plug-In Hybrid Vehicle GHG Impacts in California: Integrating Consumer-Informed Recharge Profiles with an Electricity Dispatch Model." Energy Policy 39: 1617-29.

[8] Perujo, A., and Ciuffo, B. 2010. "The Introduction of Electric Vehicles in the Private Fleet: Potential Impact on the Electric Supply System and on the Environment. A Case Study for the Province of Milan, Italy." Energy Policy 38 (8): 4549-61.

[9] Kanamori, R., Miwa, T., and Morikawa, T. 2007. "Application of Time-Dependent Stochastic Equilibrium Assignment Model Considering Activity Choices to the Nagoya Metropolitan Area." Journal of the Eastern Asia Society for Transportation Studies 7: 612-27.

[10] Kanamori, R., Miwa, T., and Morikawa, T. 2008. "Evaluation of Road Pricing Policy with Semi-dynamic Combined Stochastic User Equilibrium Model." International Journal of ITS (Intelligent Transportation System) Research 6 (2): 67-77.

[11] Next Generation Vehicle Promotion Center. "EV's Consumption." Next Generation Vehicle Promotion Center. Accessed June 1, 2014. http://www.cev-pc.or.jp/english/index.html.

[12] Oshiro, N., Oneyama, H., Yamada, T., and Ohnishi, H. 2000. "Emission Factors of Vehicles for Air Pollution Prediction near Highways." Civil Engineering Journal 42 (1): 60-3. (in Japanese)

[13] Oshiro, N., Matsusita, M., Namikawa, Y., and Ohnishi, H. 2001. "Fuel Consumption and Emission Factors of Carbon Dioxide for Motor Vehicles." Civil Engineering Journal 43 (11): 186-91. (in Japanese)

[14] Federation of Electric Power Companies of Japan. 2013. Electricity Review Japan. Japan: Federation of Electric Power Companies of Japan.

[15] Japan Institute of Energy. 2010. Cogeneration Plan and Design Manual. Japan: Japan Institute of Energy. 